\title{
PENSAMIENTO Y CULTURA EN COLOMBIA Y AMÉRICA LATINA
}



Fecha de entrega: 8 de octubre de 2008

Fecha de aprobación: 3 de marzo de 2009

\title{
APROXIMACIÓN A UNA HERMENÉUTICA ANALÓGICA
}

\author{
AN APROACH TO ANALOGICAL HERMENEUTICS
}

Mauricio Beuchot, O.P. ${ }^{1}$

\section{Resumen}

En este escrito deseo hacer una exposición introductoria de lo que es o aspira a ser una hermenéutica analógica. Para tal efecto, primero hablaré de la hermenéutica en general, con el fin de dar una idea somera de ella, pero suficiente, para después detallar lo que a la noción de hermenéutica añadiría la de hermenéutica analógica. Mas, para eso, habrá que exponer, también muy brevemente, qué es la analogía, la analogicidad, de la que toma su nombre la hermenéutica analógica, a fin de que su concepto sea comprendido más fácil y claramente.

\section{Palabras clave}

Hermenéutica, analogía, analogicidad, sentido, interpretación, diálogo, diferencia, semejanza.

\section{Abstract}

In this text I wish to make an introductory exposition about what analogical hermeneutics is or aspires to be. So, I will first talk about hermeneutics in general so that I can give a brief but sufficient idea about it and later I will detail what analogical hermeneutics is. But, in order to do that, we will have to make an exposition, also very briefly, about what analogy is, so that we can understand the concept.

\section{Key words}

Hermeneutics, analogy, sense, interpretation, dialogue, difference, similarity.

1 Universidad Nacional Autónoma de México. 


\section{Introducción}

La hermenéutica analógica ${ }^{2}$ surge como una tentativa de respuesta, como un intento de solución, o quizá de ser una puerta que saque a aires más respirables, en este momento en que la pelea entre univocismos y equivocismos ya ha fatigado demasiado a los espíritus. Por combatir el univocismo, que toma cuerpo en posturas racionalistas, cientificistas, positivistas, etc., se ha dado demasiado lugar al equivocismo, que se encarna en los relativismos, subjetivismos, escepticismos, etc., tan frecuentes en nuestro momento. Hace falta una postura intermedia, un tertium quid, una salida diferente. Y eso es lo que trata de ser la hermenéutica analógica. Pero, de acuerdo con lo dicho, comencemos explicando la idea de hermenéutica.

\section{La hermenéutica}

La hermenéutica es la disciplina de la interpretación de textos. Interpretar es comprender, en un sentido dinámico, según el cual se va profundizando cada vez más en el significado. Los textos pueden ser escritos, hablados y actuados. El texto supone un autor, que es quien lo ha producido, y un receptor o intérprete, que no siempre es el destinatario que el autor tenía en mente. Por eso, en el texto confluyen dos intencionalidades, a veces opuestas: la del autor y la del lector ${ }^{3}$. La intencionalidad del autor es lo que él quiso expresar en su texto, y la del lector es lo que él interpreta en el texto; como se ve, no siempre coinciden las dos intencionalidades, esto es, no siempre el lector interpreta en el texto lo

2 Para una exposición más detallada, véase: Beuchot (2005, pp. 35 ss.).

3 Entiéndase que aquí hablamos del lector, por antonomasia y como es usual, para abarcar no sólo a quien lee un texto escrito, sino también al oyente que escucha un texto hablado, a quien ve una acción significativa, etc. que el autor quiso que se interpretara en él; por eso algunos, como Umberto Eco, hablan de una intencionalidad del texto, que es como una vida propia que éste llega a adquirir, un mensaje bastante distinto que se produce según los distintos lectores que lo interpretan (Eco, 1992, pp. 29 ss.). Aquí se produce un conflicto de intencionalidades, y si damos la preferencia al autor, estamos propiciando una hermenéutica objetivista, que cree que se puede rescatar la intención del autor de manera muy pura y exacta; mas, en vista de que esto casi nunca es alcanzable, si damos la preferencia al lector, estamos promoviendo una hermenéutica subjetivista, la cual llega a ser a veces excesiva; por eso consideramos que se trata de buscar una solución intermedia, pero que no peque de simplismo, con una idea de término medio trivial e inútil, sino que sepa recoger ese ideal de los griegos de un término medio virtuoso, a la vez complejo y rico, difícil y fecundo, que es lo que nos guía en el fondo en la vida, ya que es la idea de virtud o areté, sobre todo de prudencia o phrónesis ${ }^{4}$.

Para interpretar un texto, se busca el contexto en el que fue producido, por eso interpretar es poner un texto en su contexto, lo cual requiere un trabajo arduo. Además de saber el idioma en el que el texto está escrito, hay que investigar al autor, su época, su cultura, sus ideas, elementos que nos puedan hablar de sus intenciones textuales. También hay que ponderar la relación que el texto tiene con nosotros, seamos o no los destinatarios que el autor quería, $\mathrm{y}$, aun en el caso de no ser esos destinatarios, precisar qué nos dice a nosotros el texto. Esto es, nos ponemos en contexto frente al texto, analizamos nuestra recepción del mismo. Por eso Gadamer decía

4 La idea de la phrónesis como el modelo de la hermenéutica, como el esquema o estructura del acto interpretativo, es una tesis principal de Hans-Georg Gadamer, uno de los más grandes hermeneutas de nuestra época (véase: Grondin, 2003, pp. 164-170). 
que toda interpretación es, al mismo tiempo, una autointerpretación. Al interpretar un texto nos colocamos frente a él (y frente a su autor).

Al interpretar un texto, al ponernos frente a él, al sentirnos interpelados por él, nos planteamos una o varias preguntas interpretativas: ¿qué dice el texto?, ¿qué quiso decir su autor?, ¿qué me dice a mí ahora?, y otras semejantes. Es como la admiración, que, según Aristóteles, nos hace investigar, $\mathrm{y}$, según Peirce, nos mueve a hacer una abducción o a lanzar una o varias hipótesis interpretativas, casi siempre más de una. Luego nos damos a la tarea de eliminar las hipótesis improcedentes, para quedarnos con las mejores o la mejor, y en ello mismo las ponemos a prueba, es decir, las contrastamos con la información que logramos recabar acerca del texto, sobre todo, para ver si podemos rescatar la intencionalidad del autor, lo que éste quiso expresar. Es decir, al elegir alguna hipótesis como principal, al tratar de apoyarla argumentativamente (aun sea con argumentación sólo retórica o tópica, y no, por supuesto, apodíctica), hacemos una deliberación, la establecemos como tesis, como juicio interpretativo o como respuesta a la pregunta interpretativa del comienzo. Según se ve, en ello se da la estructura de la prudencia o phrónesis, como quería Gadamer, pues el preguntar acerca del texto, deliberar para proponer hipótesis y elegir las más viables es el procedimiento de esta virtud. Y no sólo Gadamer sostenía eso, también Popper, el gran filósofo de la ciencia, llegaba a decir que en el trabajo científico se elegía entre dos teorías rivales no tanto por argumentación lógica sino por phrónesis, aplicando esa deliberación prudencial que nos hacía encontrar las más adecuadas y fructíferas para la investigación subsiguiente ${ }^{5}$.

5 El mismo Gadamer compara la falsación de teorías de Popper, con la phrónesis o filosofía práctica de Aristóteles: "[T]ambién cabe señalar que la teoría del trial and error desarrollada por
Por lo demás, interpretar textos es lo que hacemos primordialmente en las ciencias humanas o humanidades, concretamente en la filosofía. Por eso la hermenéutica va siendo cada vez más aceptada como un instrumento cognoscitivo importante para la filosofía. De hecho, la hermenéutica se ha colocado como lo más importante en la filosofía actual, llamada tardomoderna o posmoderna. La posmodernidad es típicamente hermenéutica, a veces con riesgo de exagerar su presencia y sus límites. Pero se ha abusado de una hermenéutica equívoca; por eso, sin caer en una hermenéutica unívoca contraria, es conveniente alcanzar una hermenéutica analógica.

\section{Hermenéutica analógica}

Para hablar de la hermenéutica analógica, una vez que hemos tratado de la hermenéutica en general, consideremos ahora la analogía, que es la noción que le sirve de vertebración. La ventaja que tenemos es que la noción de analogía tiene una ya larga tradición. Viene desde los griegos y llega hasta la actualidad; pero

Popper no se limita en absoluto a la lógica de la investigación y que, a pesar de toda la reducción y estilización de este esquema, presenta un concepto de racionalidad lógica que se extiende mucho más allá del campo de la investigación científica y describe la estructura básica de toda racionalidad, también la de la 'razón práctica'. Naturalmente, no hay que entender la racionalidad de la razón práctica sólo como la racionalidad de los medios con respecto a los fines dados. Precisamente, la formulación de nuestros fines, la formación de las finalidades comunes de nuestra existencia social, están sometidas a la racionalidad práctica, que se confirma en la apropiación crítica de las normas que nos guían en nuestro comportamiento social. De esta manera, también la posibilidad de disposición del mundo de los medios que elabora la ciencia, tiene que adecuarse a la racionalidad práctica" (Gadamer, 1981, pp. 107-108). 
ha recibido en diferentes épocas varias distorsiones, por lo que conviene tener cuidado, precaverse bien contra ellas. La analogía no es la simple semejanza, sino que en ella predomina la diferencia; es compleja, requiere que de las cosas sepamos más en qué difieren que en qué se parecen. Esta idea simplista de analogía como mera semejanza es la que, con toda razón, causó prevención y suspicacia a autores acuciosos, como Foucault, quien la denunciaba en el hermetismo renacentista, para el que todo se asemejaba a todo, indiscriminadamente (1978, pp. 26-52). Pero no, la analogía es algo mucho más serio.

La analogía es, en la filosofía del lenguaje de todos los tiempos, un modo de significación intermedio entre el unívoco y el equívoco (Eco, 1990, pp. 193 ss.). El significado unívoco pretende ser idéntico, claro y distinto; el significado equívoco es totalmente diferente e inconmensurable, sujeto a oscuridad y relativismo. En cambio el significado analógico es en parte idéntico y en parte diferente, predominando la diferencia, porque la semejanza misma así se nos muestra en la experiencia humana. "Analogía" significa proporción. Los genios de la analogía fueron los pitagóricos, filósofos presocráticos y grandes matemáticos, que introdujeron la idea de analogía en la filosofía: era la proporción, a:b:c:d, con lo cual encontraban la armonía en la música e investigaban las propiedades de las cosas en la física y en la astronomía. Sobre todo la usaron al topar con los números irracionales y con la inconmensurabilidad de la diagonal, lo cual manifiesta que la analogía o proporción ayuda a superar la irracionalidad y a acercar cosas que son inconmensurables entre sí. Los pitagóricos pasaron esta idea a Platón, que tuvo muchos maestros de esta corriente, como Timeo de Locres, Lisis, Teeteto, y otros. Platón recoge, sobre todo, la aplicación moral de la analogía o proporción, en forma de virtud (areté), en la prudencia, la templanza, la fortaleza y la justicia, según se ve en su diálogo sobre la República. Pareja utilización moral de la analogía o proporción, en el ámbito de las virtudes, se ve en Aristóteles, en su Ética a Nicómaco. Pero Aristóteles aborda la idea de analogía de una manera más teórica, especulando acerca de sus propiedades semióticas y epistemológicas. Por eso estudia la analogía en su filosofía del lenguaje, entre la sinonimia y la homonimia, esto es, entre la univocidad y la equivocidad; pero también añade, a la analogía como proporción, la analogía que después se llamará de atribución, esto es, la atribución jerárquica de un predicado, teniendo un analogado principal y analogados secundarios, según cierta gradación desde lo más propio a lo más impropio. Por ejemplo, el predicado "sano" se puede aplicar al organismo, al alimento, al medicamento, al clima, e incluso a la orina, en cuanto es signo de la salud para los médicos.

La teoría de la analogía atraviesa la Edad Media, presente sobre todo en Santo Tomás de Aquino, y, ya al llegar al renacimiento, encuentra un sistematizador en Tommaso de Vio, el cardenal Cayetano, quien le asigna una división muy recibida y aceptada. Las principales son las que ya conocemos: la analogía de atribución y la analogía de proporcionalidad, que divide en otras dos: la de proporcionalidad propia y la de proporcionalidad impropia o metafórica. La propia usa términos en sentido no figurativo o tropológico, como "El instinto es al animal lo que la razón al hombre", o "las alas son a las aves lo que las aletas a los peces", y la impropia es una clase muy importante de metáfora, la metáfora analógica, como "El prado ríe", expresión que comprendemos basándonos en la proporción siguiente: "Las flores son al prado lo que la risa al hombre", en el sentido de dar alegría. Como se ve, la analogía es muy amplia, pudiendo oscilar entre lo metafórico y lo metonímico, entre la analogía de proporcionalidad impropia o metafórica y la analogía de proporcionalidad 
propia y la de atribución, más metonímicas. Abarca la metáfora y la metonimia, que, según el semiótico Roman Jakobson (1986, pp. 381 ss.), son los dos polos del discurso humano, de nuestra racionalidad. La analogía, la analogicidad, abarca y abraza la metáfora y la metonimia, hace intersección entre ellas; por ello puede modularlas, e interpretar, cuando sea conveniente, de una manera metafórica, de una manera metonímica, o de una manera mixta entre las dos. Contiene riqueza.

La analogía casi se pierde en la modernidad, pero se refugia en los barrocos, en Giambattista Vico y en los románticos. Después de ese tiempo moderno en que fue rechazada, preterida o incomprendida (tal vez por enigmática y molesta), muchos pensadores están tratando ahora de recuperarla. Por ejemplo, alguien que enfatizó mucho la analogía hace poco fue Octavio $\mathrm{Paz}^{6}$; pero también otros más recientes, como Enrique Dussel, en México, Juan Carlos Scannone, en Argentina, y Germán Marquínez Argote, en Colombia. De hecho, hay todo un movimiento de la hermenéutica analógica en América Latina, y ya comienza a desplazarse a otras partes.

En consecuencia, la hermenéutica analógica trata de superar la distensión que se da actualmente entre las hermenéuticas unívocas y equívocas. En efecto, la hermenéutica, en toda su historia, ha sido jalonada entre el univocismo y el equivocismo, de modo que puede hablarse de una hermenéutica univocista, que restringe demasiado las posibilidades de la interpretación, y una hermenéutica equivocista, que abre en demasía dichas posibilidades, hasta el punto de que no se puede discernir entre una buena interpretación y otra incorrecta. Últimamente ha habido más tendencia a la hermenéutica equívoca, en esta época que llamamos de tardomodernidad o posmodernidad. Y, como la analogía

$6 \quad$ Puede consultarse, sobre todo, su excelente libro Los hijos del limo, 1990. está semánticamente entre la univocidad y la equivocidad, por eso ha habido necesidad de implementar una hermenéutica analógica, cuyas características pasaremos a considerar. Unas son estructurales y otras funcionales, pero obviamente están muy conectadas entre sí, guardan estrecha dependencia la una con la otra.

\section{Estructura de la hermenéutica analógica}

En cuanto a su estructura, la hermenéutica analógica tiene, como es natural, la característica de ser mediación entre una hermenéutica unívoca y otra equívoca (Beuchot, 2005, pp. 21 ss.). No tiene la rigidez de la primera, pero tampoco incurre en las extralimitaciones que cabrían en la segunda; trata de situarse como participando de ambas, aunque sin quedarse como un término medio equidistante, sino más inclinado a la diferencia. En efecto, la analogía está entre la identidad y la diferencia, pero en ella predomina la diferencia sobre la identidad. Por eso una hermenéutica analógica estará más inclinada a la equivocidad que a la univocidad (mas no por eso se derrumba en la equivocidad); es conciencia de su carácter humano y falible. Este predominio de la diferencia en la analogía tiene varias consecuencias estructurales en la hermenéutica analógica, que se reflejan en su misma vertebración interna, y que trataremos de enumerar a continuación.

Si incorporamos la analogía a la hermenéutica, tendremos una hermenéutica más amplia que la puramente univocista y más estricta que la puramente equivocista. Nos ayudará a evitar y superar la interpretación unívoca (moderna y positivista) y la interpretación equivocista (romántica y posmoderna). Una hermenéutica analógica va más allá que una hermenéutica unívoca, como la de muchos modernos y de muchos positivistas, la cual ni siquiera sería hermenéutica, pues excluye 
la polisemia o múltiple significado, y también más allá de la hermenéutica equívoca de muchos románticos y de muchos posmodernos, la cual se hunde en la polisemia irreductiblemente. En cambio, en una hermenéutica analógica se tiene la posibilidad de retomar en cierta medida la univocidad o identidad y en cierta medida la equivocidad o diferencia, pero en ella predominará esta última. Así nos hará evitar los extremos del impasse entre universalismo y relativismo. Conservará la diferencia sin perder del todo la identidad, a través de la semejanza.

Además, tendrá los distintos modos de la analogía (que se señalan en la tradición pitagórica, aristotélica y tomista), a saber, abarcará la desigualdad, la atribución, la proporcionalidad propia y la proporcionalidad impropia o metafórica. Esto último nos indica que contiene la metaforicidad. Pero la metáfora es sólo una de las formas de la analogía; ésta contiene también la metonimia, con lo cual nos da un espectro más amplio que la hermenéutica metafórica, por ejemplo, la de Ricoeur en cierto momento (1983, pp. 423 ss.). En efecto, hay una parte metafórica en la analogía, que es la proporción impropia; pero también hay analogías innegablemente metonímicas, como las de desigualdad y, más propiamente, las de atribución y de proporcionalidad propia. Si, como sostiene Jakobson, la metonimia es el origen de la ciencia y la metáfora el de la poesía, en la analogía tenemos el espacio suficiente para interpretar lo científico y lo poético respetando su especificidad, y hasta para encontrar algunos puntos en los que se toquen o entrecrucen, de manera que, en cierta medida, y sin confusión, lo científico pueda interpretarse poéticamente y lo poético científicamente.

Asimismo, la oscilación entre la analogía de atribución y la de proporcionalidad nos dará la posibilidad de contar con una aplicación jerarquizada, como es la primera, pues la atribución implica un orden gradual de aproximación al texto o a la verdad textual, y la segunda, que es más lineal o igualitaria, nos permitirá una serie de interpretaciones más próximas entre sí, y sólo diversas por la manera en que se complementan. Pero en ninguno de los dos casos se perderá la capacidad de juzgar y evaluar cuál de ellas se acerca más a la verdad del texto en cuestión, ya sea por la jerarquía de aproximación a la verdad textual, ya sea por el carácter más rico y completo que tenga.

Así, esto es abrir el ámbito de las interpretaciones sin que se vayan al infinito. No se considera válida tan sólo una interpretación, como en el positivismo, que es una hermenéutica univocista; pero tampoco se consideran todas válidas, como en algunos posmodernos, que ya transitan por una hermenéutica equivocista. En una hermenéutica analógica se pueden comparar proporcionalmente las interpretaciones, e incluso -como acabamos de decir-, usando la analogía de atribución, tener una jerarquía, una gradación, en la que haya una interpretación que sea el analogado principal y las otras los analogados secundarios, esto es, una gradación de interpretaciones en las que unas se acercan más a la verdad textual y otras se alejan de ella hasta resultar erróneas. De esta manera la interpretación deja de estar simplemente abierta hasta el infinito, y dada nuestra finitud, se acota el margen interpretativo, sobre todo por el uso del diálogo y la argumentación dentro de la comunidad hermenéutica. La hermenéutica analógica implica límite, un límite analógico, dado por el predominio de la diferencia, pero también por la presencia irrenunciable de la identidad, que obliga a cierta objetividad y no sólo a la mera subjetividad.

Asimismo, nos permite guardar un equilibrio entre la interpretación literal y la alegórica? ${ }^{7}$.

$7 \quad$ Véase la interesante polémica entre Umberto Eco, que defiende el sentido literal, y Richerd Rorty, que defiende el solo sentido alegórico, 
En efecto, una hermenéutica unívoca buscaría el solo sentido literal, desechando el alegórico; una hermenéutica equívoca buscaría el solo sentido alegórico, renunciando ya a todo sentido literal; en cambio, una hermenéutica analógica destaca el sentido alegórico que puedan tener algunos textos, pero sin perder todo sentido literal. Es un equilibrio proporcional entre la búsqueda de la intencionalidad del autor (lo que quiso decir) y la intencionalidad del lector (lo que de hecho interpreta éste), hasta el punto de permitir una lectura simbólico-alegórica, inclinada al lado de la proporcionalidad metafórica, sin perder por ello la capacidad de reducirla lo más que se alcance a la atribución de literalidad. Porque la tensión hacia la literalidad (sólo tensión) es la que impide la caída en el mero subjetivismo interpretativo.

Por lo mismo, nos permite oscilar, como en un gradiente, entre la interpretación metonímica y la metafórica. Abarca esos dos polos y se mueve entre uno y otro. Algunos textos sólo permitirán una interpretación metonímica; otros, una metafórica; pero habrá otros que oscilen entre una y otra, y la hermenéutica analógica nos permitirá ajustar el gradiente entre ambas, según lo requiera la proporción de metonimia o la proporción de metáfora que se encuentre en los textos. Esto nos ayudará a aplicar, según se necesite, la metonimicidad y la metaforicidad según el caso, para no forzar los textos que sólo admitan la una o la otra, $\mathrm{y}$, sobre todo, para una lectura más rica de los que admitan las dos. Resultará, así, una interpretación enriquecida pero seria.

La hermenéutica analógica, asimismo, nos ayudará a captar el sentido sin renunciar a la referencia; es decir, inclusive a privilegiar al primero, pero sin relegar a la segunda. Es muy notorio que la hermenéutica actual prefiere el sentido, que viene por la coherencia o por la convención, y relega la referencia, que viene

en: Eco, 1995, pp. 96 ss. por la correspondencia y la verificación. Casi la desprecia o le teme. En la línea del sentido, hay una tendencia a la equivocidad, pues el sentido resulta de cada mente o sistema; en cambio, en la línea de la referencia, hay una tendencia a la univocidad, pues pertenece a la pretensión cientificista. De hecho, los univocismos, como el del positivismo lógico, han sido referencialistas, con una pretensión tan ingenua de conocer unívocamente la referencia, que los ha hecho desembocar en relativismos muy fuertes, por el desplome de esa rigidez tan extrema. En cambio, sus críticos, como Davidson y Rorty, por ejemplo, más en la línea pragmatista de la analítica (y el pragmatismo se ha caracterizado por ser anti-positivista), han resaltado los equívocos referenciales, la equivocidad que en ocasiones padece la referencia; y esto los ha movido a negar la referencia misma (Davidson, 1984, pp. 227 ss.). Con todo, se puede adoptar una postura intermedia o analógica, en la que, sin pretender una relación referencial biunívoca entre las palabras y las cosas, se evite el caer en el rechazo de toda referencia, y se acepte una referencialidad más dinámica, incluso movediza, pero suficiente. No pretender que la referencia sea inequívoca, pero tampoco negarle toda adecuación a lo real.

La hermenéutica analógica nos ayudará a tener una interpretación a la vez sintagmática y paradigmática -en el sentido del estructuralismo-, aunque es preponderantemente la segunda. Mueve a no separar las dos como irreconciliables, sino a tratar de ver el punto en el que se entrecruzan, en el que se unen en el trabajo que se realiza, de modo que se pueda avanzar en profundidad, con el movimiento no sólo de oposición de lo sintagmático y horizontal, sino también, con el de asociación de lo pragmático y vertical, que cala hondo, que asocia y ve lo que se repite, encontrando en ello su novedad, como una continua novedad del eterno retorno de lo mismo pero diferente (esto es: lo análogo). 
Los monjes medievales leían los salmos en sentido paradigmático, asociativo, pues los relacionaban con toda la Escritura, y reiterativo, pues los cantaban muy buen número de veces; pero cada vez que se repetían eran diferentes, enseñaban algo nuevo, cada vez se veía distinto lo mismo.

Tiene como instrumento principal la distinción, y por ello requiere del diálogo. Es eminentemente dialógica. En efecto, el diálogo es el que obliga a distinguir, y la distinción hace encontrar con sutileza el medio entre dos extremos que se presentan como cuernos de un dilema, pues la distinción -como señalaba Peirce (1988, pp. 201-203)- tiene la estructura de un silogismo dilemático o razonamiento alternativo. Si tomamos una de las alternativas, caemos en contradicción o en problemas; si adoptamos la otra, también. Entonces hay que buscar un tercer término, un término medio, que nos ayude a introducir otra u otras alternativas, que sean nuevas posibilidades, las cuales nos permitan salir de la contradicción, que generalmente se da en los extremos.

De hecho, la hermenéutica presupone una antropología filosófica o filosofía del hombre en la que el ser humano está caracterizado por su humildad ante el saber. Sabe que puede no saber, que se puede equivocar, que puede engañarse o ser engañado. Sobre todo, que puede no tener razón. Eso impele a sospechar y a distinguir. El ejercicio de la sospecha, en efecto, va muy asociado a la distinción, pues ella es el procedimiento por el que se busca salir del error posible. Distinguir es lo más hermenéutico, y la distinción es un acto sumamente analógico, ya que trasciende la identidad pura y la diferencia pura, para colocarse en la analogía, la cual se reconoce como no pura, aunque sabe también que no es completamente impura. Es la mediación en la que predomina la diferencia.
Igualmente, una hermenéutica analógica nos hará combinar y equilibrar proporcionalmente lo monológico y lo dialógico. Es cierto que se necesita el diálogo, y no lo hemos de negar; pero en este tiempo en que tanto se resalta el diálogo, se tiende a olvidar, como lo señala bien Javier Muguerza, que las principales decisiones (morales, políticas, etc.), las tomamos en momentos de reflexión, de monólogo, o de diálogo sólo con nosotros mismos. Se trata de la reflexión compartida en el diálogo, y del diálogo sustentado en la reflexión: una reflexión dialogada y un diálogo reflexivo.

Además, una hermenéutica analógica nos ayudará a superar la dicotomía entre descripción y valoración, cosa tan importante para la ética y la política, pues corresponde a la dicotomía tan tajante entre hecho y valor, la cual lleva a establecer la llamada falacia naturalista, que señala como inválido el paso del ser al deber ser, de los enunciados descriptivos a los valorativos, lo cual impide una fundamentación de lo moral y político en el estudio de la naturaleza humana. La hermenéutica analógica, en cambio, nos hace ver que no hay tal falacia, sino que, como lo enseñan la retórica (y la pragmática), todo enunciado descriptivo tiene una fuerza ilocucionaria valorativa (como lo mostró Searle) $\mathrm{y}$, por lo mismo, no se infiere más de lo que tiene, sino que sólo se explicita el contenido que ya posee en sí mismo.

Finalmente, una hermenéutica analógica ayuda a superar la dicotomía de Wittgenstein entre el mostrar y el decir. Wittgenstein separaba demasiado, sin punto de conciliación ni solución de continuidad, el decir y el mostrar. El decir era lo científico, y el mostrar lo místico. Lo que no se podía decir, sólo se podía mostrar. Y, según él, las cosas más importantes de la vida, como lo ético, lo estético y lo religioso, no se pueden decir; sólo se pueden mostrar. Sin embargo, la analogía fue usada por muchos místicos para poder decir de algu- 
na manera lo que estaba destinado a mostrarse solamente. Frente a la teología positiva, en la que se pretendía decir mucho acerca del misterio, se estableció la teología negativa (en la línea judía, como en Filón, Maimónides, etc., y en la línea cristiana oriental, como en Juan Damasceno, Gregorio Palamás, etc.). Pero también se buscó una línea intermedia, como se ve en el Pseudo-Dionisio, cuando no se lo ve sólo como teólogo negativo, sino buscando la vía de la eminencia; algo parecido sucede en Santo Tomás, en Eckhart, San Juan de la Cruz y otros. La analogía es decir el mostrar y mostrar el decir. Sobre todo tratar de decir lo que sólo se podía mostrar. Pero se sabía que eso únicamente era posible hasta cierto punto, en muy pequeña medida, como balbuciendo, con un gran predominio de las imágenes y las metáforas, sobre el discurso directo y literal. Sin embargo, se consiguió al menos lo suficiente para decir algo del misterio, sin quedarse irremediablemente callado.

Se ve, así, que la estructura de la hermenéutica analógica es la de la disciplina de la interpretación, o la hermenéutica misma, que además trata de vertebrar en su seno la analogía como característica de su acción interpretativa. Se trata de una interpretación analógica, la cual pretende tener más sutileza de la que admite la univocidad, que corre el peligro de pecar de sobre-simplificación, pero, a la vez, más rigor que la que admite la equivocidad, la cual corre el peligro de abrir demasiado el espectro de las interpretaciones. $\mathrm{Su}$ principal instrumento es la distinción, más que el afirmar y el negar; es decir, trata de buscar la mediación entre las posturas contrarias y contradictorias, para intentar la integración de lo que de válido pueda encontrarse en ellas. Y esto es más difícil y complejo que el solo aceptar o rechazar en bloque. En este punto se puede ver cierta semejanza con el pensamiento integracionista que promovió el gran filósofo español, ahora desaparecido, José Ferrater Mora (Echevarría, 1994, pp. 107 ss.).

\section{Funciones de la hermenéutica analógica}

En cuanto a las funciones de la hermenéutica analógica, resultan de la estructuración que hemos señalado en ella. Al oscilar entre la univocidad y la equivocidad, puede ejercer funciones de integración, salvaguardando la diferencia, pero sin perder completamente toda reducción a la identidad; aunque, como ya se ha dicho, en ella predomina la diferencia. Tratemos de señalar algunas de esas funciones.

Evitar los inconvenientes de una hermenéutica unívoca y una hermenéutica equívoca. El primer tipo de hermenéutica es demasiado restrictivo, incluso reduccionista; el segundo es demasiado abierto, incluso emergentista hasta el infinito. Se superará el reduccionismo de la sola interpretación válida, pero también el emergentismo desbocado de las infinitas interpretaciones válidas y complementarias; se tendrá un conjunto amplio de interpretaciones válidas, pero definido y con la posibilidad de jerarquía, es decir, un conjunto ordenado, en el que se ven los grados de aproximación a la verdad textual, de modo que llega un punto en el que se alejan de ella e incurren en la falsedad. Eso permite el juego de la subjetividad y la objetividad; se reconoce el predominio de la subjetividad, sin abandonar por ello la capacidad de objetividad que debe tener la interpretación. Es lo que la analogía de atribución permite hacer, en la cual hay un analogado principal y varios analogados secundarios; es decir, se podrá establecer una interpretación principal, en el sentido de más rica, más fecunda, más apropiada o adecuada, sin pretender, por supuesto, que agote toda la verdad textual, que tenga con el texto una adecuación o correspondencia que las demás nunca van a tener; y las otras 
pueden convivir con ella, pero sabiendo que son complementarias de la misma, que ven otros aspectos, que exploran otras aristas; con ello la interpretación ciertamente se enriquece, pero no se abre desmesuradamente, de modo que permite varias interpretaciones, pero con límites y con medida, es decir, con proporción, con analogía.

\section{Frenar el relativismo de la interpretación} infinita, asi como la inconmensurabilidad completa, cosas que van con el equivocismo. De hecho, se superará el impasse que ahora se ve en hermenéutica, por su distensión hacia los dos extremos del universalismo y el relativismo. Ayuda a abrir los márgenes de la interpretación, pero sin que pierdan su carácter de fronteras o límites. Se amplía la diferencia sin perder la posibilidad de cierta identidad (por la semejanza), se abre la diversidad sin perder la universalidad. Se universalizará a posteriori, y a partir del diálogo. No estableciendo una meta-filosofía impositiva y opresora, sino una dia-filosofía, que surge desde abajo, y va integrando características universalizables de las distintas culturas. Ya que la analogía surgió (desde los pitagóricos) para conmensurar de alguna manera lo inconmensurable, nos da la posibilidad de hacer conmensurables las culturas, de modo que se puedan criticar y también sea posible aprender de ellas; todo ello mediante el diálogo, en lo cual consiste la mencionada dia-filosofía.

Esto tiene algo de la hermenéutica diatópica, de Raimon Panikkar (1997, p. 46) y de Boaventura de Souza Santos (2003, p. 38), que es una hermenéutica que trata de resaltar las particularidades sin perder lo universal. Esto es lo que en la hermenéutica analógica se ve con el predominio de la diferencia, que nunca anula completamente la porción de identidad, al menos como semejanza, que es lo que permite universalizar. De otra manera, se perdería la posibilidad de defender los derechos humanos, los cuales requieren al menos algo de universalidad en la cual apoyarse.

Integra sin confundir, reduce dicotomías sin que se mezclen en extremo. Tal es la virtud de la analogía. Se parece a algunas filosofías del límite, como la de Eugenio Trías, y a algunas filosofías de la mediación, como la de Andrés Ortiz-Osés -ambos lo han comentado-, a saber, aquellas que postulan que en el límite los extremos se tocan, que el límite es para que pisemos los dos lados del mismo, que el límite es para ser transgredido, pero no por la violencia, sino por la astucia, por la delicada trampa o truco que permita superarlo, traspasarlo, sin violentarlo.

El tratar de reducir dicotomías, pero de una manera coherente, ha sido peculiar del pragmatismo. Sobre todo se ve en Peirce (pero también en James y Dewey), que trata de no separar tanto lo teórico y lo práctico, lo analítico y lo sintético, y, hasta diría yo, lo universal y lo particular. Peirce pone como ideal la terceridad, es decir, el pensamiento en el que entre dos extremos se encuentra un tercero, siempre mediador. Es la difícil labor de la intermediación, que es cierta síntesis dialéctica, equilibrio, mesura, proporción, es decir, analogía. El pensamiento analógico está llamado a buscar síntesis, mediación entre opuestos (como lo vio Nicolás de Cusa).

Cuando decimos que en la analogía predomina la diferencia sobre la semejanza, queremos decir que en una hermenéutica analógica se puede privilegiar lo diferente sin perder la semejanza. Es posible manejar lo movedizo sin hundirnos en el pantano; se puede jugar con distintas interpretaciones, a veces osadas, sin perder el carácter fronético o prudencial que nos permita regresar a la orilla, hincar el ancla de modo que no nos lleve la corriente ni el remolino. Por eso, una hermenéutica analógica sería la verdadera filosofía no prepotente ni impositiva, que no edifica meta-relatos, sino dia-relatos, los cuales son muy distintos. 
Este carácter de dia-relato, de dia-filosofía, que ya se mencionó, está muy cerca -según vimos- de la hermenéutica diatópica de $\mathrm{Pa}$ nikkar, que privilegia lo particular, pero sin perder lo universal; sólo que, en lugar de buscar universales culturales, busca invariantes humanos. Son formas parecidas de esfuerzo por salvaguardar la diferencia, la diversidad, pero siempre en el marco de la universalidad, de algo que asegure y garantice la capacidad de universalización que se requiere incluso para el diálogo.

Interpretar correctamente el símbolo, evitando los extremos de quienes desean interpretarlo unívocamente, encontrando los mismos símbolos en las diferentes culturas, reduciéndolos a una interpretación positivista o traducción cientificista de los mismos, y el de los que los interpretan equívocamente, esto es, dicen que de hecho no se pueden interpretar, que sólo se pueden vivir. Son los extremos de la teología positiva y la teología negativa; la primera pretendía decirlo todo, la segunda prefería no decir nada; entre una y otra se establece una postura analogista, que trata de decir sin decir, esto es, de decir lo más posible sin pretender decirlo todo, pues eso equivaldría a no decir nada. Una hermenéutica analógica del símbolo respetaría lo inefable del mismo, reconocería su carácter de irreductible o inexhaustible, pero se atrevería a decir algo de él, a interpretarlo de manera sólo aproximativa, proporcional (ya que proporción es lo que la misma analogía significa).

Aquí sí he encontrado un punto de discrepancia con Panikkar. En un congreso, en la Universidad Pontificia de México, en 1994, él afirmaba que el símbolo no se interpreta, se vive. Lo argumentaba diciendo que solamente el que ha nacido en una cultura, como la india, puede entender los símbolos de la misma. En cambio, creemos que un símbolo de otra cultura se puede interpretar, claro que con pérdida; pero se puede tratar de aprender qué significa, y acercarse a su comprensión, al menos por analogía. Esa discrepancia se nota más en un libro posterior de Panikkar (1998, p. 30), en el que hay un capítulo con el título "Es un discurso polisémico que no puede ser ni siquiera analógico", aludiendo al discurso religioso, el cual no puede tener a alguna religión o a alguna deidad como analogado principal. Allí se ve este alejamiento de Panikkar respecto de la analogía.

Permite conjuntar, en el límite, hermenéutica y ontología, lenguaje y ser, sentido y referencia. Es cuando logramos hacer lo que quería Heidegger en Ser y tiempo, esto es, interpretar el ser, traer el significado hacia el significante, la suposición hacia la significación, el objeto hacia el concepto, el ente hacia el lenguaje. Lingüistizar la ontología, pero también ontologizar el lenguaje; buscar una ontología disminuida en sus pretensiones de presencia fuerte, pero también una hermenéutica disminuida en sus pretensiones de ausencia de representación, sin fuerza representativa, porque es tan caínico o fratricida lo uno como lo otro.

De acuerdo con ello, puede abrir a una cierta ontología, una ontología analógica, acorde con una hermenéutica analógica (Díez, 2001, pp. 80 ss.). Esa nueva ontología auténticamente analógica será verdaderamente débil, la verdadera metafísica débil del pensiero debole que propugna Vattimo. Al hacernos ver que el símbolo tiene una cara hermenéutica y otra ontológica, nos ayudará a recobrar la simbolicidad para el hombre, lo cual repercutirá en la ontología, en la antropología o la psicología, y en la sociología, así como en la ética y la política. Abrirá, primeramente, a un replanteamiento de la ontología o metafísica, y después ello afectará a todas las demás ramas de la filosofía y aun a las ramas de la ciencia.

Así como puede superar la falacia naturalista, y hacer que construyamos válidamente una ética desde nuestro conocimiento del 
ser humano, de su naturaleza, esto es, desde una ontología de la persona, también puede ayudarnos a construir una filosofía política que supere los desencuentros del liberalismo y el comunitarismo, en una síntesis más rica, que privilegie a este último, es decir, que propicie las diferencias de las comunidades, pero sin perder los logros innegables del liberalismo, como los derechos humanos, esto es, que evite la exclusión. Con ello se podrá acceder a una mejor respuesta al problema del multiculturalismo, tan presente en nuestros países latinoamericanos, esto es, a un pluralismo cultural analógico, dentro de un marco democrático.

Y, por lo mismo, permite hacer una filosofía propiamente latinoamericana, pero inserta en la filosofía universal, mundial (Muñoz, 2005 , pp. 32 ss.). Ya que la analogía es la percepción de lo particular en lo universal, pero sin caer en el relativismo y el absolutismo, nos da los elementos para hacer filosofía latinoamericana, pero sin salirse del seno de lo universal. De hecho, la hermenéutica analógica tiene componentes que le dan un estatuto altamente latinoamericano. La analogicidad fue usada en el encuentro entre las culturas española e indígena. Gran parte de lo que se trabajó de no-destructivo, de constructivo, de positivo y conveniente, fue por obra de la analogía. La analogía permitió a Bartolomé de las Casas captar el humanismo indígena, y no sólo el humanismo europeo. Si humanistas eurocentristas, como Ginés de Sepúlveda (que era propiamente el humanista y el avanzado), condenaban a los indios en nombre del humanismo renacentista, y los acusaban de crímenes de lesa humanidad (sacrificios humanos, antropofagia, etc.), Las Casas supo ver, por analogía con el humanismo de griegos y romanos (que hacían sacrificios humanos, por ejemplo), el humanismo indígena, y trató de comprenderlo. Es una actitud eminentemente hermenéutica y analógica, esto es, hermenéutico-analógica.
La analogía es el punto central del barroco mexicano y latinoamericano, en el que se da con más fuerza ese fenómeno tan nuestro del mestizaje. Cuando ya las razas no estaban tan ocupadas en destruirse, por la fuerza del eros y de la vida, se fusionan y engendran ese análogo que es el mestizo. Sobre todo surge el mestizaje cultural, de productos culturales nuevos y distintos, que ya no son propiamente españoles ni propiamente indígenas, sino algo nuevo. En el mismo simbolismo del barroco se ve la presencia de la analogía, de la analogicidad, en ese juego de metáfora y metonimia, las cuales se mueven con tanto dinamismo en esa época. Sandoval y Zapata es un ejemplo de ello, con su poesía tan lograda; pero más aún es un paradigma Sor Juana, que sabe integrar lo conceptista y lo culterano en su magno poema Primero sueño. También se ve ese mestizaje cultural en Sigüenza y Góngora, que, en su Teatro de virtudes políticas, cuando todos ponían como ejemplos de tales virtudes gobernantes griegos y romanos, él prefirió ejemplos tomados de entre los gobernantes indígenas.

También en el siglo XVIII la analogía es utilizada por el genial jesuita Francisco Xavier Clavigero, en su Historia antigua de Méxi$c o$, en la que la aplica para entender y dar a entender la cultura azteca. Sobre todo a los europeos, y principalmente a los Ilustrados, contra los que disputa, contestando a aquellos que menoscababan tanto la dignidad de los indígenas americanos, como Buffon, Raynal, De Pauw y otros. Curiosamente, ellos eran los avanzados y, sin embargo, estaban en contra de los indígenas; los acusaban de inmadurez culpable. No eran capaces de reconocer la dignidad humana que proclamaban para los ciudadanos de la Europa. Y, en cambio, este jesuita criollo, ciertamente ilustrado en alguna medida, pero todavía anclado en su escolástica, como ecléctico que era, supo reconocer la alta dignidad de los indígenas, con los cuales él mismo cuenta que había 
convivido directamente, y que ahora defendía en las disputaciones con las que adornaba su historia.

Igualmente, encontramos la analogía en Octavio Paz, gran poeta mexicano, premio Nobel de Literatura y reconocido intelectual. Él hacía de la analogía el núcleo de lo poético, y, siguiendo a Roman Jakobson, decía que la metáfora y la metonimia eran formas de la analogía; por lo cual la analogía era el núcleo del pensamiento humano. Asimismo, ha habido otros pensadores latinoamericanos que han hecho uso de la analogía en su síntesis sistemática, como Enrique Dussel y Juan Carlos Scannone, ambos originarios de Argentina, ya naturalizado mexicano el primero. Ellos la usan en relación con la dialéctica, en forma de analéctica, y gracias a su inteligente utilización, me enseñaron a usarla en la hermenéutica, en forma de hermenéutica analógica. También fue usada por otro filósofo mexicano, que trabajó en Venezuela, Adolfo García Díaz, quien hizo su tesis acerca de la analogía en Santo Tomás, publicó artículos sobre el tema, y le daba un alto valor en la lógica y la epistemología. Igualmente, fue cultivada por otro eminente filósofo de México, originario de Italia (Florencia) y que se había radicado después en Venezuela, pero que ha trabajado la mayor parte del tiempo en México: Alejandro Rossi, quien, en su discurso de ingreso a El Colegio Nacional, dice que el primer curso que dictó en la UNAM fue sobre la analogía en Santo Tomás; la actitud analogista le quedó para siempre, por influjo de sus estudios sobre Wittgenstein y por su amistad tan estrecha con Octavio Paz, el gran poeta analogista, y Rossi lo manifestó en su obra, tanto filosófica como literaria.

Según se ve, una hermenéutica analógica responde a un uso de la analogía en filosofía que tiene ya una larga tradición, tradición que también abarca el cultivo de esta disciplina en
América Latina. De manera especial, ayudará a superar los pensamientos que se clausuran en sistemas cerrados y en totalidades excluyentes. Es un recurso del pensamiento que ha servido para comprender la alteridad, sin las pretensiones de completa conversión a una otredad absoluta, pues eso es meramente ilusorio, sino que, dentro de ciertos límites, se abre a la comprensión del otro, pero brindándole la crítica que surge de la propia ubicación en el mapa de la cultura.

\section{El acto de interpretación analógico}

Recogiendo lo que hemos dicho, y tratando de ejemplificar un poco, veamos cómo es, puede ser, o tiene que ser, el acto de interpretación que resulta de una hermenéutica analógica. En primer lugar, recordemos que la analogía es proporción, por lo que el acto interpretativo analógico buscará en un texto la proporción que toca al autor, al lector y al mismo texto en cuanto al significado. Es decir, hay un significado del autor y un significado del lector que, sintetizados, configuran el significado del texto. En una interpretación analógica, que trata de evitar la univocidad del sentido literal, la cual es inalcanzable, a saber, qué dijo verdaderamente el autor, y dado que en la analogía predomina la diferencia sobre la identidad, se dará predominio al significado del lector, sin que esto redunde en desprecio del significado del hablante o autor. No es dejar de lado el significado o intencionalidad del autor, es simplemente la conciencia y el reconocimiento de que es imposible de alcanzar, y que siempre va a predominar nuestra subjetividad. Sin embargo, también es advertencia de que no por eso nos hemos de resbalar hacia el equivocismo del mero sentido alegórico, según el cual nada, absolutamente nada, se puede recuperar de la intencionalidad del autor y todo se reduce a una producción de sentido que, a la postre, 
nos hunde en el mar del relativismo y hasta de la incomprensión.

Para lograr esa proporción, esa proporcionalidad que hay que hacer con las intencionalidades del autor y del lector, la interpretación analógica tiene como instrumento la distinción. Distinguir los significados de un texto lleva a evitar el equívoco y también a rechazar la pretensión unívoca de la claridad total; es darse cuenta de que donde quiera está la posibilidad del múltiple significado, de la polisemia o multivocidad, pero también de que siempre acecha la equivocidad, y que se tiene que acudir a la analogía para espantarla. De hecho, la multivocidad es doble: equívoca o análoga; la primera es irreductible, la segunda es manejable. Por eso la analogía nos ahuyenta el fantasma de la equivocidad total, de la que ya no hay salida.

El genial lógico y pragmatista Charles Sanders Peirce decía que la distinción evita el dilema, el argumento dilemático, esa situación en la que nos encontramos sin salida. En el ámbito de la hermenéutica, es encontrarnos con dos interpretaciones igualmente insostenibles, o igualmente sostenibles, pero que no conducen a la comprensión. Según ese autor, el dilema se produce por una enumeración insuficiente, por no contar con todas las posibilidades o hipótesis, y eso se logra distinguiendo. Si se nos presentan sólo dos interpretaciones problemáticas, hay que saber encontrar y postular una tercera, o introducir una cuarta, etc. Y para ello se requiere sutileza, la cual, significativamente, era la virtud que se atribuía a los buenos intérpretes. Hacer distinciones relevantes e interesantes, fructíferas, ayuda a encontrar nuevas interpretaciones, a lanzar buenas hipótesis hermenéuticas, que nos ayuden no sólo a salir de las situaciones difíciles, de interpretaciones rivales insuficientes, o igualmente cuestionables, sino a encontrar interpretaciones más adecuadas al texto $\mathrm{y}$, sobre todo, más ricas y fecundas para nosotros.
Y es que, en efecto, para llevar al límite el símil, podemos comparar la situación hermenéutica o el acontecimiento interpretativo con una situación dilemática, incluso paradójica, en la que nos encontramos, en un extremo, con dos interpretaciones rivales, cada una de las cuales nos lleva a una contradicción, o a una consecuencia indeseable, como ocurre en el argumento dilemático, donde cada una de las opciones lleva al absurdo. Por eso era llamado silogismo cornuto, según algunos por San Jerónimo, ya que los dos cuernos del dilema daban la impresión de un toro que embestía, y en el que, por evitar un cuerno, se caía mortalmente en el otro (Beuchot, 2004, pp. 97-98). Pero se hablaba jocosamente de romper los cuernos del dilema, y esto se hacía introduciendo la distinción, como haciendo acrobacias con el toro, para burlarlo. Pues bien, la sutileza, la distinción, es algo eminentemente analógico; era usada por los lógicos antiguos para evitar precisamente los dos cuernos de la univocidad y de la equivocidad. Por eso el propio Peirce, excelente lógico, hablaba de la analogía como capacidad de distinción (1988, p. 202), de encontrar matices, diferencias, diversos sentidos que nos hagan escapar a la simplificación univocista $\mathrm{y}$ al enredo equivocista.

También hay que decir que la hermenéutica analógica es toda una experiencia. Jugando con la distinción kantiana entre lo empírico y lo trascendental, Johannes Lotz intituló uno de sus libros sobre el tema: La experiencia trascendental, dando a entender que sólo acercando a lo empírico lo trascendental, a pesar de que Kant los separaba demasiado, se puede acceder a la propuesta epistemológica que allí se desarrollaba, aquí también nos gustaría jugar con los términos y hablar de una experiencia hermenéutico-analógica, dado que la hermenéutica y la analogía no están tan alejadas de lo empírico, ni tampoco de lo trascendental. Se ha de llegar a la conformación de una virtud hermenéutico-analógica, 
es decir, de una virtus interpretativa, que asimile y haga propia la experiencia de la analogía, que ponga en práctica lo que hace que una interpretación sea analógica, lo que nos permite hablar de una hermenéutica basada en la analogía.

\section{Conclusión}

Así, el pensamiento analógico, en forma de hermenéutica analógica, puede servir para romper los extremos de la cerrazón que impide comprender, así sea mínimamente, al otro, y el de la apertura sin fin, que no es real, sino meramente imaginaria, si no es que fingida, y nos coloca en el punto medio frágil y movedizo del que trata de comprender, pero sabiendo que su comprensión no será absoluta, que tendrá pérdida, pero que, con todo, resultará suficiente, pues es la única que se puede alcanzar al nivel humano de nuestra limitada comprensión. Será un conocimiento que nos permita criticar al otro desde nosotros $\mathrm{y}$, asimismo, criticarnos a nosotros mismos desde el otro, es decir, escuchar e incorporar lo más que se pueda las enseñanzas que nos proporciona, dentro del diálogo enriquecedor que se entabla.

La hermenéutica analógica privilegia la diferencia, pues esta última predomina en la analogía por encima de la identidad. Retomando una expresión de Lévinas, su manera de defender la diferencia será combatiendo la indiferencia que suele darse entre los seres humanos. Con ello se habrá protegido la diferencia de una manera no acrítica y sin límites, sino dentro del marco de la convivencia social pacífica y justa.

\section{Referencias}

Beuchot, M. (2004). Introducción a la lógica. México: UNAM.

Beuchot, M. (2005). Perfiles esenciales de la hermenéutica. (4ta ed.). México: UNAM.

Beuchot, M. (2005). Tratado de hermenéutica analógica. Hacia un nuevo modelo de interpretación. (3ra ed.). México: UNAM-Ítaca.

Davidson, D. (1984). Inquiries into Truth and Interpretation. Oxford: Clarendon Press.

Díez G., R. (2001). Hacia una ontología analógica, acorde con una hermenéutica analógica. En Vertebración (UPAEP, Puebla), vol. 14/52, pp. 80-93.

Echeverría, J. (1994). El integracionismo de José Ferrater Mora: una filosofía abierta al porvenir. En Giner, S. \& Guisán, E. (eds.). José Ferrater Mora. El hombre y su obra. (pp. 107-125). Santiago de Compostela: Universidad de Santiago de Compostela.

Eco, U. (1990). Semiótica y filosofía del lenguaje. Barcelona: Lumen.

Eco, U. (1992). Los límites de la interpretación. Barcelona: Lumen.

Eco, U. (1995). Interpretación y sobreinterpretación. Cambridge: Cambridge University Press.

Foucault, M. (1978). Las palabras y las cosas. (10a ed.). México: Siglo XXI.

Gadamer, H. G. (1981). La razón en la época de la ciencia. Barcelona: Alfa.

Grondin, J. (2003). Introducción a Gadamer. Barcelona: Herder.

Jakobson, R. (1986). Ensayos de lingüística general. México: Origen-Planeta. 
Muñoz, V. (2005). Hermenéutica analógica y filosofia latinoamericana (tesis de maestría). México D.F., UNAM, Maestría en Filosofía.

Panikkar, R. (1997). La experiencia filosófica de la India. Madrid: Trotta.

Panikkar, R. (1998). Iconos del misterio. Barcelona: Península.
Paz, O. (1990). Los hijos del limo. Barcelona: Seix Barral.

Peirce, Ch. S. (1988). Escritos lógicos. Castrillo, P. (ed.). Madrid: Alianza.

Ricoeur, P. (1983). La metáfora viva. Madrid: Ediciones Europa.

De Souza Santos, B. (2003). La caída del Angelus Novus: ensayos para una nueva teoría social y una nueva práctica politi$c a$. Bogotá: ILSA/UNC. 